\title{
Role of Pharm.D in Better Patient Care: Perspective of Indian Health Care Practitioners
}

\author{
Rajesh Venkataraman, Muhammed Rashid*, Mary Cherian, Ashna Abraham, Shahinur Islam, Gloriya \\ Grifth Manuel
}

Department of Pharmacy Practice, Sri Adichunchanagiri College of Pharmacy, Adichunchanagiri University, BG Nagara, Mandya, Karnataka, INDIA.

\begin{abstract}
Background: Clinical Pharmacists (CP) are less prized in direct patient care compared to both physicians and nurses even though most of the professionals identified that the CP is an inexorable part of the medical team. Objectives: To explore the perception of Health care Practitioners (HCPs) towards the Pharm.D and Services provided by the CPs from the Indian perspective. Methodology: A 10 items questionnaire-based cross-sectional survey was conducted through surveying HCPs including medical, nursing, pharmacy and the academician about their perceptions regarding the Pharm.D program and the clinical pharmacy services providing by the CPs in a tertiary care teaching hospital situated in the south Indian state Karnataka. Results: A total of 130 volunteers participated including 91 medical doctors or students, 6 pharmacists who work in the hospital, 17 nurses, 3 academicians and other 13 didn't mention their profession. In the study, $91.54 \%$ (119) accepted that CPs can play a vital role in improving the medication adherence through the patient counselling and $92.31 \%$ (120) HCPs were agreed that CPs can provide appropriate interventions for better patient care. Their efforts in drug interactions and ADRs are really appreciated and $82.31 \%(107)$ recommended CP as an integral part of the multidisciplinary health care team. Conclusion: Our research suggests that CPs can be an asset to the health care practice especially in India through partnering the HCPs in better patient care by providing the appropriate interventions. Still, there is an emergent need for more practical emphasised syllabus and curriculum to make the Pharm.D graduates more employable.
\end{abstract}

Key words: Pharm.D, Clinical Pharmacy, Health care Professional, Perspective, Patient care Main Text.

\section{INTRODUCTION}

\section{Pharmacy in India}

Pharmacy and Pharmaceutical Science is a growing field in India. Even though Clinical Pharmacy (CP) is in its infancy, it is having a great influence on patient care and started being a part of the healthcare system in India. Pharmacy is a connecting bond between the chemical and health sciences to confirm the appropriate safe and effective use of medicines or drug products and it comes into existence over the experiences and efforts amassed over thousands of years. ${ }^{1}$ The history of Pharmacy began long back from the $6^{\text {th }}$ Century, by evidence the Vedic period was till $800 \mathrm{BC}$ and subsequently Brahmanic period till $1000 \mathrm{AD}^{1}$ Arabic or UnaniTibb system of medicine was initiated and boomed in India followed by Muslim ruling, but which was overtaken by the allopathic system of medicine when the British ruled India. Drugs started flowing from Europe in early 19 s and started manufacturing in India by $1940 .^{2}$ The first education regulations outlined in 1953 by The Pharmacy Council of India (PCI) which was established in 1949 under "Ministry of Health" and the same was amended afterwards in 1972, 1981 and $1999 .^{3}$

\section{Doctor of Pharmacy or Pharm.D}

Pharm.D is a pre-Ph.D, post-graduate professional degree with a complete oneyear internship training in speciality units. During the sixth year, they are supposed to provide the clinical pharmacy services in General medicine for six months and in any other speciality clinics for rest of the year. The course has been introduced in India and
DOI: 10.5530/ijopp.13.1.10

Address for correspondence: Mr. Muhammed Rashid, Assistant Professor, Department of Pharmacy Practice, Sri Adichunchanagiri College of Pharmacy, Adichunchanagiri University, BG Nagara-571448, Karnataka, INDIA.

Phone no: +919886880633 Email Id: muhammedrashid2@ gmail.com

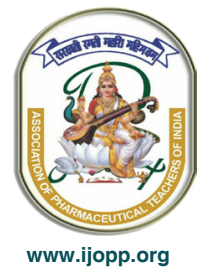


made the Pharm.D regulations by PCI under section 10 of the Pharmacy Act, 1948 (8 of 1948) in 2008. ${ }^{4,5}$ Still, Pharm.D is under-recognized even though it is the only pharmacy programme having direct contact with patients and providing patient-oriented services. So, there is a huge job sparsity among Indian Pharm.D graduates. ${ }^{6}$

\section{Clinical Pharmacy and Clinical Pharmacist}

Clinical pharmacy practice is the practice of pharmacy in a multi-disciplinary health care team which is oriented to achieve the treatment goals by ensuring the right patient receives right medication in the right dose, prevent the drug-related problems through medication chart review and achieving therapeutic goals by improving medication adherence through patient counselling. ${ }^{7}$

Pharmaceutical Care Services providing by a clinical pharmacist includes medication history interview, ward round participation, prescription order review/ medication chart review, drug/poisons information service, medication error monitoring, assessing, preventing and managing the drug interactions, ADR assessment and management, clinical review, selection of drug therapy, therapeutic drug monitoring, promoting the safe and quality use of medicine and the services in liaison with community pharmacies such as health screening camps, awareness programs etc. ${ }^{4,8}$

$\mathrm{CP}$ is less appreciated $(\phi<0.05)$ in direct patient care compared to both physicians and nurses even though most of the professionals identified that the CP is an inexorable part of the medical team in providing the quality of patient care through their practice. 'They accept and prefer Pharm.D's in both private and government sector to provide better patient care and to improve medication adherence. Moreover, some doctors believe that CPs should update and discuss the prescription chart after putting their interventions each day. ${ }^{10}$ Physician admitting that CPs can provide relevant drug information and can detect and prevent drug-related problems. ${ }^{11}$

Thus, the rationale for conducting this study is to explore the perception of Healthcare Practitioners (HCPs) towards the Pharm.D and Services provided by the CPs from the Indian perspective. Thus, as an initiation, a closed type cross-sectional survey was conducted in the south part of India to study the perception of HCPs towards the Pharm.D and the clinical pharmacy services provided by the CPs.

\section{MATERIALS AND METHODS}

A cross-sectional study was conducted by surveying HCPs including medical, nursing, pharmacy and the academician about their perceptions regarding the Pharm.D programme and the clinical pharmacy services providing by the CPs in a tertiary care teaching hospital situated in the south Indian state Karnataka. The survey was conducted on "World Pharmacist Day" i.e: 25 September 2018 by providing a closed type questionnaire in English which has to be filled by them. Only the HCPs excluding Pharm.D students who are currently studying or practising the clinical pharmacy activities were included.

Researchers were approached the professional with a questionnaire, the survey completion was voluntary, participants were able to decline their participation and did not receive any compensation for completing the survey. The study population was also asked to inscribe the information such as their name/initial, profession, qualification and the designation.

A 10-items closed type self-explanatory paper made questionnaire was provided which has to be filled by the pen or pencil further the same data was transferred to an electronic form (Google form). The questionnaire was framed in such a way to understand their perception regarding the Pharm.D and clinical pharmacy services. The data were retrieved using Microsoft Excel 2013 and the results were described in percentage and in the form of pie charts. The data were analysed in IBM SPSS V.14 and it was presented in the descriptive pattern. Results were presented in the form of descriptive statistics and the chi-square test was used to find out the distribution of responses as the dependent variable was categorical and the sample was one.

\section{RESULTS}

\section{Demographics of the participants}

A total of 130 volunteers participated in the survey. By profession they were medical doctors or students (91) including MBBS interns, PG students, surgeons, ophthalmologist, dentist, physiotherapist etc., pharmacists (6) who works in the hospital (other than Pharm.D students), nurses (17), academician (3) and 13 didn't mention their profession. The distribution of the participants is illustrated Figure 1.

\section{Perception of HCPs on Pharm.D}

Our research revealed that 5.38\% (7) HCPs were completely unaware of what is Pharm.D even after a decade of the introduction of the course to India. Most of the HCPs $91.54 \%$ (119) accepted that CPs can play a vital role in improving the medication adherence through the patient counselling and $92.31 \%$ (120)HCPs 
were agreed that CPs will help in effective patient care by providing appropriate interventions which is a major CP activity.

When we consider CP as a drug information provider, 90\% (117) of HCPs agreed that Pharm.D graduate is an accurate and appropriate source of drug and poison information. Surprisingly, 92.31\% (120) of HCPs acknowledged that CPs are having the capability of detecting, assessing, monitoring and preventing the ADRs and can encourage and develop the pharmacovigilance programmes. By recognizing all these clinical activities of the Pharm.D students, 51.54\% (67) of HCPs suggested that Pharm.D interns deserve "Dr" designation along with their name and $88.46 \%$ (115) suggested that CP should be there in every hospital to ensure appropriate use of medicine.

Among the HCPs participated, 82.31\% (107) recommended $\mathrm{CP}$ as a part of the multidisciplinary health care team to achieve better patient care and 90.77\% (118) advised that there is the scope of improvement in the Pharm.D curriculum. The perception of HCPs about Pharm.D provided in Table 1 and the percentage of volunteers who supported Pharm.D and Clinical pharmacy through their positive response is illustrated in Figure 2.

\section{DISCUSSION}

Pharmacy education in India has been established way back in 1899 first in Madras and then in Bengal in the year of 1928. ${ }^{12}$ Diploma in Pharmacy (D.Pharm), Bachelor of Pharmacy (B.Pharm), Master of Pharmacy (M.Pharm), Master of Science in Pharmacy [MS(Pharm)] and Master of Technology in Pharmacy [MTech (Pharm)], Doctor of Pharmacy (Pharm.D) and Doctor of Philosophy (Ph.D) in Pharmacy are the pharmacy courses currently running in India under various government, non-government, private and deemed universities. The pharmacy practices in different countries gradually vary especially in developing countries like India, because the training is more industrial oriented. ${ }^{13}$

In this $21^{\text {st }}$ Century, CP is booming like anything in India. ${ }^{14}$ But, still, some of the HCPs are not well aware of the Pharm.D and their role in health care practice. Our research suggests that 5.38\% (7) of the HCPs are not aware of what Pharm.D is and 49 (37.69\%) think that both PP and CP are the same. Where, PP include CP which assess the patient care and therapy ${ }^{15}$ and PP cover clinical pharmacy, pharmacotherapy, pharmaceutical care, clinical research and socio -administrative care.

Treatment is seeing to be non-effective nowadays because of their improper compliance or non-adherence to therapy which in turn lower the quality of life. ${ }^{16}$ As CPs are more close to the patients in their daily routine practice, they can more get involve or engage in promoting medication adherence by providing proper counselling and awareness. ${ }^{17}$ In our research, $119(91.54 \%)$ HCPs agreed and shared that CPs can encourage the patients for better medication adherence.

\begin{tabular}{|c|c|c|c|c|}
\hline SI. No. & Question or Query & $\begin{array}{l}\text { Yes; Number } \\
\text { (\%) }\end{array}$ & $\begin{array}{c}\text { No; } \\
\text { Number (\%) }\end{array}$ & $\begin{array}{l}\text { Chi-Square } \\
\text { value; } p \text { value }\end{array}$ \\
\hline 1 & Do you know what Pharm.D is? & $\begin{array}{c}123 \\
(94.62)\end{array}$ & $\begin{array}{c}7 \\
(5.38)\end{array}$ & $8.481 ; 0.075$ \\
\hline 2 & $\begin{array}{c}\text { Do you think Pharmacy Practice and Clinical Pharmacy are the } \\
\text { same? }\end{array}$ & $\begin{array}{c}49 \\
(37.69)\end{array}$ & $\begin{array}{c}81 \\
(62.31)\end{array}$ & $16.406 ; 0.003$ \\
\hline 3 & $\begin{array}{c}\text { Can Pharm.D play a vital role in improving medication adherence } \\
\text { through patient counselling? }\end{array}$ & $\begin{array}{c}119 \\
(91.54)\end{array}$ & $\begin{array}{c}11 \\
(8.46)\end{array}$ & $9.740 ; 0.045$ \\
\hline 4 & $\begin{array}{l}\text { Will Pharm.D help in improving patients' health by providing } \\
\text { appropriate interventions? }\end{array}$ & $\begin{array}{c}120 \\
(92.31)\end{array}$ & $\begin{array}{c}10 \\
(7.69)\end{array}$ & $4.825 ; 0.306$ \\
\hline 5 & $\begin{array}{l}\text { Can Pharm.D help you in accessing and providing accurate and up- } \\
\text { to-date drug information? }\end{array}$ & $\begin{array}{l}117 \\
(90)\end{array}$ & $\begin{array}{c}13 \\
(10)\end{array}$ & $43.970 ; 0.000$ \\
\hline 6 & Pharm.D will plays a vital role in Pharmacovigilance (Drug Safety)? & $\begin{array}{c}120 \\
(92.31)\end{array}$ & $\begin{array}{c}10 \\
(7.69)\end{array}$ & $13.437 ; 0.009$ \\
\hline 7 & Pharm.D deserves "Dr." designation before their name? & $\begin{array}{c}67 \\
(51.54)\end{array}$ & $\begin{array}{c}63 \\
(48.46)\end{array}$ & $8.304 ; 0.081$ \\
\hline 8 & $\begin{array}{c}\text { We need Pharm.Ds in every hospital as a part of multidisciplinary } \\
\text { healthcare team? }\end{array}$ & $\begin{array}{c}115 \\
(88.46)\end{array}$ & $\begin{array}{c}15 \\
(11.54)\end{array}$ & $18.983 ; 0.001$ \\
\hline 9 & $\begin{array}{l}\text { Do we need improved strategies to ensure quality of Pharm.D } \\
\text { education in India? }\end{array}$ & $\begin{array}{c}118 \\
(90.77)\end{array}$ & $\begin{array}{c}12 \\
(9.23)\end{array}$ & 6. $082 ; 0.193$ \\
\hline 10 & Will you accept Clinical Pharmacist as your health care Partner? & $\begin{array}{c}107 \\
(82.31)\end{array}$ & $\begin{array}{c}23 \\
(17.69)\end{array}$ & $11.447 ; 0.022$ \\
\hline
\end{tabular}




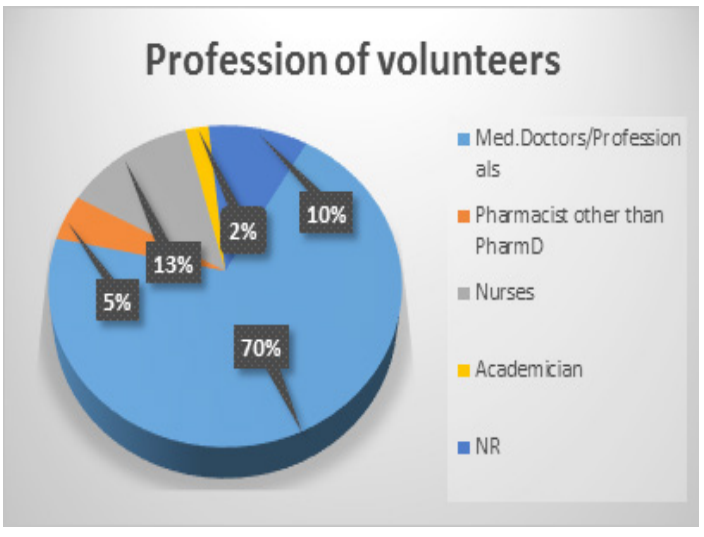

Figure 1: Distribution of participants.

Medication errors frequently occur in a clinical field that should be detected, reported and prevented in inpatient wards by appropriate interventions by $\mathrm{CPs}^{18}$ and 120 (92.31\%) HCPs were agreed that interventions by CPs will help them to reduce the medication errors as well as other drug-related problems.

Provision of drug and poison information is an important role of CP in health care practice and 90\% (117) of the HCPs in our survey conveyed that $\mathrm{CP}$ can provide authentic and updated information to their queries. Sridevi et al. reported that drug information providing by CP was very much helpful in promoting better patient care as most of the queries was related to updated knowledge and guidelines. ${ }^{19}$ Moreover, CP can take an appreciable role in drug safety and can involve in pharmacovigilance activities such as detection, assessment, understanding and reporting of ADRs and nowadays they are trained to do so. ${ }^{20}$ Nowadays, there is a number of literature and publications which addresses the rare occurrence of ADRs followed by the administration of various drugs in patients including paediatrics, adults and also in geriatrics. ${ }^{21-23}$ This all represents that CPs are actively involving in various pharmacovigilance activities. Surprisingly, 92.31\% (120) participants agreed that Pharm.D can play a vital role in pharmacovigilance.

By considering all these efforts about half $51.54 \%$ (67) of the total HCPs show a positive attitude towards the doctorate designation for Pharm.D and $88.46 \%$ (115) professionals stand for the need of Pharm.D in every hospital as a part of the multidisciplinary healthcare system and $82.31 \%$ (107) professionals accept Pharm.D as a healthcare partner. These results are showing that HCPs deadly need the CPs in their healthcare team which will help to provide better patient care. There is a need of dramatic change in the syllabus to improve the quality of Pharm.D education in India and 90.77\% (118) professionals agreed this. Quality of education can be improved by the concept of quality teaching, personalized

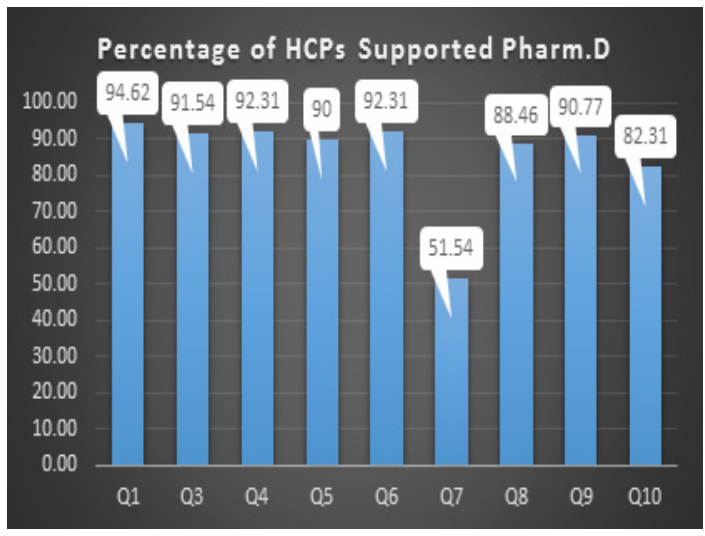

Figure 2: Percentage of HCPs who supported Pharm.D.

counselling centres for students, ${ }^{24}$ adopting multimedia resources, creating friendly atmosphere and emphasis on more of clinical and practical knowledge which will help to make the students more employable. We were restricted to only one hospital in a rural area and the study can be further extrapolated to other hospitals as well as the other parts of the country.

\section{CONCLUSION}

Our research suggests that Pharm.D and CPs can be an asset to the health care practice especially in India by partnering the HCPs in better patient care. They can provide the appropriate interventions to avoid the drugrelated problems and other irrational drug use. Most of the HCPs was recommending the need for CPs as their healthcare partner in patient care. Still, there is an emergent need for more practical emphasised syllabus and curriculum to make the Pharm.D graduates more employable.

\section{ACKNOWLEDGEMENT}

Authors would like to thank students of Department of Pharmacy Practice especially Aksa Merin Jose, Jerin S Shaji and Leveena Mathew for their help in the distribution of questionnaire among the healthcare professionals.

\section{CONFLICT OF INTEREST}

Authors declare no conflict of interest

\section{ABBREVIATIONS}

ADR: Adverse Drug reaction; B.Pharm: Bachelor of pharmacy; CP: Clinical Pharmacists/Clinical Pharmacy; D.Pharm: Diploma in Pharmacy; HCPs: Healthcare practitioners; MBBS: Bachelor of Medicine, Bachelor of Surgery; M.Pharm: Master of pharmacy; PG: Post Graduate; Ph.D: Doctor of Philosophy.

Indian Journal of Pharmacy Practice, Vol 13, Issue 1, Jan-Mar, 2020 


\section{SUMMARY}

Pharm.D has to be well recognized in India and needs to be considered as part of the health care team. It is very clear that all HCPs identified and agreed that, Pharm.D can play a vital role in all aspects of medication related activities which can turn into a better patient outcome. However, the current strategy of Pharm.D curriculum and teaching methodology needs to follow the international standards in upcoming days.

\section{REFERENCES}

1. Rana RD. Pharmacy in ancient India. Indian J Hist Sci. 1987;22(2):119-21.

2. Karim S, Adnan M. Pharmacy practice in India. In Pharmacy Practice in Developing Countries. 2016;117-46.

3. Desale P. An overview about pharmacy education in India. Indian Journal of Research in Pharmacy and Biotechnology. 2013;1(3):329.

4. Gaur A, Deepak K, Ranjan R, Kaur M, Kaur T. Current Scenario of Pharm.D Program of India. International Journal of Current Medical and Pharmaceutical Research. 2018;4(2):2972-5.

5. Bhuyan B. Pharmacy Education in India: Current Standard, Admission Criteria and Regulation. International Journal of Pharma and Bio Sciences. ;4(2):860-6.

6. Nathan KT, Conn K, Birnie CR. Assessing student perceptions of the Pharm. D. degree at a private tertiary medical university in India. Pharmacy Education. 2017;17(1):335

7. Parthasarathi G, Nyfort-Hansen K, Nahata MC. A Text Book of Clinical Pharmacy Practice: Essential Concepts and Skills. Orient Blackswan. 2004;496.

8. Deshpande PR, Farooq KK, John DM, Rao EJ. Pharm D: A new concept in India. Journal of Pharmacy and Bioallied Sciences. 2012;4(1):84-6. DOI: 10.4103/0975-7406.92746

9. Al-Arifi MN, Alghamdi B, Al-Saadi M, Idris AE, Wajid S, Said R, et al. Attitudes and perceptions of healthcare providers towards clinical pharmacy services at a tertiary care hospital in Riyadh, Saudi Arabia. Tropical Journal of Pharmaceutical Research. 2015;14(5):913-8.

10. Garipelly R, Garg S, Mateti UV. Emerging doctor of pharmacy program in India: A survey on general opinion of selected educated Indians. Journal of Research in Pharmacy Practice. 2012;1(2):48. DOI: 10.4103/2279-042X.108370

11. Ahmad A, Srikanth BA, Patel I. Indian Pharm. D: Should it be pursued?. Archives of Pharmacy Practice. 2014;5(2):97.

12. Tharappel LJ, Kaur G, Buttar HS. Pharmaceutical Education in India: Past, Present and Future. Journal of Pharmaceutical Sciences and Research. 2014;6(8):278.
13. Sachan A, Sachan AK, Gangwar SS. Pharmacy education in India and its neighbouring countries. International Current Pharmaceutical Journal. 2012;1(9):294-301.

14. Mazhar M, Ansari A, Rajput SK. Clinical pharmacy in India: Recent advances and perspective. Pharma Tutor. 2015;3(3):31-6.

15. Jacobi J, Ray S, Danelich I, Dodds Ashley E, Eckel S, Guharoy R, et al. Impact of the Pharmacy Practice Model Initiative on clinical pharmacy specialist practice. Pharmacotherapy: The Journal of Human Pharmacology and Drug Therapy. 2016;36(5):e40-9. https://doi.org/10.1002/phar.1745

16. Khayyat SM, Mohamed MM, Khayyat SM, Alhazmi RS, Korani MF, Allugmani $\mathrm{EB}$, et al. Association between medication adherence and quality of life of patients with diabetes and hypertension attending primary care clinics: A crosssectional survey. Quality of Life Research. 2018;1-9. https://doi.org/10.1007/ s11136-018-2060-8

17. Taitel M, Jiang J, Rudkin K, Ewing S, Duncan I. The impact of pharmacist faceto-face counseling to improve medication adherence among patients initiating statin therapy. Patient Preference and Adherence. 2012;6:323-9. https://dx.doi. org/10.2147\%2FPPA.S29353

18. Khalili H, Mohebbi N, Hendoiee N, Keshtkar AA, Dashti-Khavidaki S. Improvement of knowledge, attitude and perception of healthcare workers about ADR, a pre-and post-clinical pharmacists' interventional study. BMJ Open. 2012;2(1):e000367. doi: 10.1136/bmjopen-2011-000367.

19. Sridevi K, Subbaiah MV, Surekha M, Harini J, Chandini S, Basher S, et al. Clinical Pharmacist Role in Drug Information Services and Medication Errors Management At Tertiary Care Hospital. IOSR Journal of Dental and Medical Sciences. 2017;16(6):16-23.

20. Toklu HZ. Pharmaceutical education vs. pharmacy practice: Do we really teach what they need for practicing. Journal of Pharmaceutical Care and Health Systems. 2015;3:e001.

21. Singh J, Tyagi S, Jangra MS, Rashid M, Chhabra M, Tripathi KR. Ataxia, Manifestation of Phenytoin Toxicity: A Case Report. Journal of Young Pharmacist. 2019;11(1):112. DOI: http://dx.doi.org/10.5530/jyp.2019.11.x

22. Peedikkal MR, Sebastian J, Ramesh M, Doddaiah N, Prashanth SN. Gingival Overgrowth on Chronic use of Amlodipine: A Case Report. Indian Journal of Pharmacy Practice. 2017;10(4):299. DOI: http://dx.doi.org/10.5530/ ijopp.10.4.61

23. Lucca JM, PP MR, Ninan R, Chonde G. Carbimazole Induced Cholestatic Hepatitis: A Case Report. European Journal of Pharmaceutical and Medical Res. 2017;4(10):362-4.

24. Jishnu V, Gilhotra RM, Mishra DN. Pharmacy education in India: Strategies for a better future. Journal of Young Pharmacist. 2011;3(4):334. https://dx.doi. org/10.4103\%2F0975-1483.90248 